\title{
Disease-modifying drug initiation patterns in commercially insured multiple sclerosis patients: a retrospective cohort study
}

\author{
Jay M Margolis ${ }^{1 *}$, Robert Fowler², Barbara H Johnson², Cheryl A Kassed ${ }^{3}$ and Kristijan Kahler ${ }^{4}$
}

\begin{abstract}
Background: The goal of this research was to compare the demographics, clinical characteristics and treatment patterns for newly diagnosed multiple sclerosis (MS) patients in a commercial managed care population who received disease-modifying drug (DMD) therapy versus those not receiving DMD therapy.

Methods: A retrospective cohort study using US administrative healthcare claims identified individuals newly diagnosed with MS (no prior MS diagnosis 12 months prior using ICD-9-CM 340) and $\geq 18$ years old during 20012007 to characterize them based on demographics, clinical characteristics, and pharmacologic therapy for one year prior to and a minimum of one year post-index. The index date was the first MS diagnosis occurring in the study period. Follow-up of subjects was done by ICD-9-CM code identification and not by actual chart review. Multivariate analyses were conducted to adjust for confounding variables.

Results: Patients were followed for an average of $35.7 \pm 17.5$ months after their index diagnosis. Forty-three percent $(n=4,462)$ of incident patients received treatment with at least one of the DMDs during the post-index period. Treated patients were primarily in the younger age categories of 18-44 years of age, with DMD therapy initiated an average of $5.3 \pm 9.1$ months after the index diagnosis. Once treatment was initiated, $27.7 \%$ discontinued DMD therapy after an average of $17.6 \pm 14.6$ months, and $16.5 \%$ had treatment gaps in excess of 60 days.
\end{abstract}

Conclusions: Nearly $60 \%$ of newly-diagnosed MS patients in this commercial managed care population remained untreated while over a quarter of treated patients stopped therapy and one-sixth experienced treatment gaps despite the risk of disease progression or a return of pre-treatment disease activity.

\section{Background}

Multiple sclerosis (MS) is a complex, recurrent, and progressive autoimmune disease of the central nervous system affecting an estimated 250,000 to 400,000 people in the US. Primarily diagnosed in young adults at a mean age of 29 years, it follows four recognized disease courses: relapsing/remitting MS (RRMS), secondary progressive MS (SPMS), primary progressive MS (PPMS), and progressive relapsing MS (PRMS) [1-4]. Approximately $20 \%$ of patients have a mild form of the disease, yet MS can also render a person unable to write, speak, or walk, with up to $60 \%$ of patients losing ambulatory

\footnotetext{
* Correspondence: jay.margolis@thomsonreuters.com

'Thomson Reuters, 332 Bryn Mawr Ave., Bala Cynwyd, PA, 19004, USA

Full list of author information is available at the end of the article
}

capability within 20 years after onset $[1,2,5]$. Since most people with MS have a fairly normal life expectancy, this chronic disease evokes very significant social, medical and economic impacts.

MS is neither easy nor quick to diagnose, especially in its early stages, compounded by the often transient nature of attacks, variability in symptoms, other diseases producing similar symptoms, and the lack of a specific unequivocal diagnostic test $[1-4,6,7]$. Clinical diagnosis often requires several strategies to determine if a person meets the established criteria (e.g., The Revised McDonald Criteria), including a detailed medical history, neurologic exams, magnetic resonance imaging (MRI), evoked potentials (EP) and spinal fluid analysis [7-9]. Symptoms may vary in frequency, severity and form, and so patients diagnosed with clinically definite MS

\section{Biomed Central}


will typically have been through several diagnostic stages often drawn out over months or years [10-17].

There is presently no known cure for MS. Current treatments for MS are aimed at returning function after an attack, preventing new attacks, managing symptoms and preventing or postponing long-term disability [18]. Acute symptomatic attacks are most often treated with high dose glucocorticoids, however there does not appear to be any long-term functional benefit from their use $[18,19]$. Several disease-modifying drugs (DMDs) have been found to reduce the relapse rate, reduce lesion development, positively affect MRI metrics and disease progression, and improve the quality of life for many MS patients [3,18,20-23]. Six parenterally administered DMDs are currently approved for immunomodulatory and immunosuppressive treatment of relapsing and secondary-progressive MS (in alphabetical order): glatiramer acetate, interferon beta 1a-intramuscular, interferon beta 1a-subcutaneous, interferon beta $1 \mathrm{~b}$, mitoxantrone, and natalizumab [21]. DMD treatment can be sustained indefinitely, as long as there is evidence of benefit, particularly since cessation of therapy may result in returning to pre-treatment disease activity [21,24-29].

The decision to begin or continue MS therapy is complex and controversial [5]. The National Multiple Sclerosis Disease Management Consensus Statement [21] recommends initiating interferon beta or glatiramer DMD therapy as soon as possible following definite diagnosis of active, relapsing MS, and also to consider DMD therapy for selected high risk patients with a first attack. Although the DMDs have positively affected the treatment and course of RRMS, numerous factors including their parenteral route of administration, injection anxiety, side effects, unobservable improvement, adjunctive therapy, and treatment fatigue can affect the initiation and continuation of DMD therapies [5,17,23,25-29].

The objective of the current research was to understand the differences in demographics, clinical characteristics and treatment patterns between newly diagnosed MS patients in a commercial managed care population who received DMD therapy versus those not receiving DMD therapy.

\section{Methods}

\section{Study design}

This retrospective cohort study used administrative healthcare claims from a database of US-based employers and health insurers to identify individuals newly diagnosed with MS during 2001-2007 and to construct a detailed claims history for each individual. Patients were characterized based on their demographics and baseline clinical indicators (diagnoses, comorbidities, concomitant medications) during the year prior to the index diagnosis, and then followed for at least one year to assess healthcare resource utilization, medical expenditures, treatments, and adherence to therapy.

\section{Data source}

Data came from two Thomson Reuters MarketScan ${ }^{\circledR}$ research databases: the Commercial Claims and Encounters (Commercial) database and the Medicare Supplemental and Coordination of Benefits (Medicare) database, from January 1, 2000, through December 31, 2007. The Commercial database contained the inpatient, outpatient, and outpatient prescription drug experience of 44.5 million employees and their dependents under a variety of insurance coverage types. The Medicare database contained the healthcare experience of 4.5 million individuals with Medicare supplemental insurance paid for by employers, including both the Medicare-covered portion of payment and the employer-paid portion. All database records were de-identified and fully compliant with US patient confidentiality requirements (HIPAA).

\section{Sample selection and study period}

Selected patients were a minimum of 18 years old with a diagnosis of MS (ICD-9-CM code 340) between January 1, 2001, and January 1, 2007 (patient selection period). A minimum of one inpatient or emergency department claim, or more than one outpatient claim at least 30 days apart with ICD-9-CM 340 (excluding diagnostic laboratory and diagnostic radiology claims; also referred to herein as "non-diagnostic" claims) was required. The index diagnosis date was assigned to the earlier of the first medical claim with an MS diagnosis or the date of the first medical or pharmacy claim for one of the DMDs during the patient selection period. Patients were required to have at least 12 months of continuous health plan eligibility with both medical and pharmacy benefits both before and following their index diagnosis date. To identify patients as "incident" or newly diagnosed, they were required to have no claims with a diagnosis of MS or any DMD therapy during the 12-months prior to their index diagnosis date. The study used administrative claims data in the absence of the patient medical charts, therefore relying on the diagnoses coded by the provider and the patient history found only within the healthcare claims. Patients were followed for a minimum of 12 months from their index date and then for as long as the data were available or until the end of calendar year 2007. Follow-up of subjects was done by ICD-9-CM code identification and not by actual chart review.

\section{Outcome measures}

Diagnoses, medical procedures and pharmacologic therapy were derived from medical and pharmacy claims 
received according to service dates in the patient's preindex and post-index periods. MS diagnoses and comorbidities were determined from medical claims (excluding diagnostic laboratory and radiology claims). A diagnosis code entered in any position for the claim was used. Pharmacologic therapy was identified from pharmacy claims and from HCPCS codes in medical claims. Medical procedures or diagnostic evaluations were identified from CPT-4 codes or ICD-9-CM procedure codes in medical claims. Drugs for treating MS were analyzed individually and by drug class.

Demographic data included age, gender, insurance plan type (comprehensive, EPO, HMO, POS, POS with capitation, PPO, and other), geographic region and length of follow-up. Clinical data included monitoring for selected comorbidities in medical claims, computation of the Deyo-Charlson comorbidity index (measured pre-index), use of DMD therapy, other pharmacological treatments for MS symptoms, and medical procedures and diagnostic tests associated with MS.

Treatment pattern analyses included time to DMD therapy initiation (for patients treated), persistence on therapy and discontinuation patterns. The length of continuous treatment with the index DMD was determined by considering the days supplied listed on the index drug claim(s), as well as the fill date and days supplied for subsequent claims of the same medication, including medical claims showing DMD administration. The length of index DMD therapy was defined as "continuous" by calculating days across consecutive prescription or medical claims of the index drug with no gaps of more than 30 days. A gap between consecutive prescriptions of the index drug is typically allowed because patients may not fill prescriptions the exact day they are due for a refill. The number of patients with gaps in therapy of 31-60 days, 61-90 days, 91-120 days and $>120$ days were also tracked. Gaps for patients receiving natalizumab and mitoxantrone were adjusted to accommodate for their longer dosing intervals, assuming 4 weeks for each medical claim date for natalizumab and 12 weeks from each medical claim date for mitoxantrone $[30,31]$. As a part of the gap analysis, the number of patients with evidence of the index DMD after a gap of $>60$ days ("restarts") were identified and the average number of days to restart was measured. The length of DMD therapy from the first until the last drug claim of the index DMD was also measured. This measure counted the number of days between the treatment index date (i.e., the first drug claim for the index medication) and the last drug claim for the index medication (including days of supply) during the study period, regardless of gaps in therapy. The length of continuous treatment with all DMD therapy was measured, both with and without gaps of greater than 30 days. For each patient's drug regimen, the time from the first DMD claim to the date of the last applicable DMD claim (including days of supply) was measured, including any DMD therapy that was received. Switching among DMDs and discontinuation of all DMDs (i.e., no evidence of any DMD for a 60-day period following the end of the last observed prescription) was also analyzed.

\section{Statistical analysis}

Categorical variables were presented as counts and proportions. Continuous variables were summarized by providing the number of observations, the mean, the standard deviation, the median, and the range. Statistical tests of significance for differences in these distributions included Chi-square tests to evaluate the statistical significance of differences for categorical variables, $t$-tests and ANOVA for normally distributed continuous variables, while nonparametric Wilcoxon and KruskalWallis tests were used for continuous variables that are not normally distributed. P-values of 0.050 or less were considered statistically significant.

Multivariate regressions were conducted to control for imbalances in observed baseline demographics and clinical characteristics. Cox proportional hazards regressions were used to assess characteristics associated with treatment initiation with adjustment for time from diagnosis to first treatment as well as to assess treatment persistence, measured as the time to a 31 day gap in therapy, among those treated. A logistic regression model was also used to predict patient characteristics affecting the initiation of treatment with DMDs. For each of the three models, age and gender were included as covariates and a backward elimination method was employed to select among the many other characteristics, with the variables remaining in each model each statistically significant at a level of $5 \%$. All statistical analyses were performed using SAS version 9.2.

\section{Results}

\section{Sample Attrition}

Initially there were 67,869 Commercial and Medicare patients with at least one inpatient or two non-diagnostic outpatient claims at least 30 days apart with an MS diagnosis between January 1, 2001 and January 1, 2007. Of these, 34,699 (51.1\%) were excluded after applying twelve months pre- and post-index continuous eligibility requirements, $306(0.5 \%)$ were excluded who were under the age of 18 , and 21,803 patients (32.1\%) were excluded who had an MS diagnosis or DMD treatment during the pre-index period, resulting in a final cohort of 11,061 patients.

\section{Demographics}

Population demographics are shown in Table 1. Females comprised $74.2 \%$ of the study population. The average 
Table 1 Patient Population Demographics

\begin{tabular}{|c|c|c|c|}
\hline Demographic & All patients & DMD-treated & Not DMD treated \\
\hline & $N=11,061$ & $n=4,462$ & $n=6,599$ \\
\hline \multicolumn{4}{|l|}{ Gender } \\
\hline Male & $25.8 \%$ & $23.7 \%$ & $27.2 \%$ \\
\hline Female & $74.2 \%$ & $76.3 \%$ & $72.8 \%$ \\
\hline Age (in years, mean \pm SD) & $50.3 \pm 13.3$ & $44.5 \pm 10.6$ & $54.3 \pm 13.4$ \\
\hline $18-34$ & $11.5 \%$ & $18.4 \%$ & $6.8 \%$ \\
\hline $35-44$ & $21.5 \%$ & $30.4 \%$ & $15.5 \%$ \\
\hline $45-54$ & $31.2 \%$ & $33.5 \%$ & $29.7 \%$ \\
\hline $55-64$ & $22.5 \%$ & $15.6 \%$ & $27.2 \%$ \\
\hline $65+$ & $13.2 \%$ & $2.2 \%$ & $20.7 \%$ \\
\hline \multicolumn{4}{|l|}{ Insurance Type } \\
\hline Commercial & $85.1 \%$ & $96.9 \%$ & $77.1 \%$ \\
\hline Medicare & $14.9 \%$ & $3.1 \%$ & $22.9 \%$ \\
\hline \multicolumn{4}{|l|}{ Geographic Region } \\
\hline Northeast & $12.9 \%$ & $12.8 \%$ & $13.0 \%$ \\
\hline North Central & $35.6 \%$ & $32.0 \%$ & $38.0 \%$ \\
\hline South & $30.4 \%$ & $35.5 \%$ & $27.0 \%$ \\
\hline West & $20.5 \%$ & $19.2 \%$ & $21.3 \%$ \\
\hline Unknown & $0.6 \%$ & $0.5 \%$ & $0.7 \%$ \\
\hline \multicolumn{4}{|l|}{ Index year } \\
\hline 2001 & $7.5 \%$ & $8.0 \%$ & $7.2 \%$ \\
\hline 2002 & $12.9 \%$ & $13.0 \%$ & $12.9 \%$ \\
\hline 2003 & $16.8 \%$ & $17.7 \%$ & $16.1 \%$ \\
\hline 2004 & $24.0 \%$ & $22.1 \%$ & $25.4 \%$ \\
\hline 2005 & $22.2 \%$ & $22.5 \%$ & $21.9 \%$ \\
\hline $2006^{*}$ & $16.6 \%$ & $16.7 \%$ & $16.5 \%$ \\
\hline Length of follow-up (in months, mean \pm SD) & $35.7 \pm 17.5$ & $36.7 \pm 17.6$ & $35.1 \pm 17.5$ \\
\hline
\end{tabular}

*Patients who indexed on January 1, 2007 are included in 2006 category

length of follow up was $35.7 \pm 17.5$ months. There were $40.3 \%(\mathrm{n}=4,462)$ of patients treated with at least one of the DMDs during the study period. The mean population age was $50.3 \pm 13.3$ years, with DMD-treated patients significantly younger (mean age $44.4 \pm 10.6$ years) than those without DMD treatment (mean age $54.3 \pm 13.4$ years, $\mathrm{p}<0.001)$. The age distributions show skewing of treatment to younger age groups, with $48.8 \%$ of DMD-treated patients under the age of 44 compared with $23.3 \%$ of untreated patients, and $2.2 \%$ of patients over 65 with DMD treatment versus $20.7 \%$ of untreated patients.

\section{Clinical characteristics}

Chronic pain conditions were the most frequently noted comorbidities in the medical claims of this MS population (Table 2), with over half of the cohort reporting chronic skeletal pain (joint derangements, dorsopathies, or polymyalgia rheumatica). With the exception of fatigue, headache, depression, skin cancers, and sleep disorders, all other comorbidities were noted in significantly higher percentages of patients not treated with DMDs. The Deyo-Charlson Comorbidity Index was calculated for all patients, measured using pre-index comorbidities, and was significantly lower for DMDtreated patients, computed at $0.36 \pm 0.86$ for DMD-treated patients and $0.64 \pm 1.24$ for untreated patients, $\mathrm{p}<$ 0.001 .

\section{Treatment patterns}

The most common index DMD used in treating these incident patients was glatiramer $33.7 \%$ of treated incident patients) followed by interferon-beta-1a IM (32.1\%) and interferon-beta-1a SQ (20.5\%) (Table 2). The start of availability for interferon beta-1a SQ in the US in February, 2002 is acknowledged as a factor possibly underestimating its relative reported usage over the fiveyear time span of this study. Similarly, it is noted that 
Table 2 MS Comorbidities and Pharmacologic Treatments of Interest During the Post-Index Period

\begin{tabular}{|c|c|c|c|}
\hline Comorbidity* & $\begin{array}{l}\text { DMD-treated } \\
(n=4,462)\end{array}$ & $\begin{array}{l}\text { Not DMD treated } \\
(n=6,599)\end{array}$ & p-value \\
\hline Joint derangement, dorsopathies, polymyalgia rheumatica & $52.7 \%$ & $57.1 \%$ & $<0.001$ \\
\hline High blood pressure & $30.5 \%$ & $40.7 \%$ & $<0.001$ \\
\hline High cholesterol & $23.2 \%$ & $28.6 \%$ & $<0.001$ \\
\hline Cancers excluding skin cancer & $22.2 \%$ & $28.2 \%$ & $<0.001$ \\
\hline Fatigue & $25.1 \%$ & $24.1 \%$ & 0.231 \\
\hline Urinary tract infections & $21.6 \%$ & $25.9 \%$ & $<0.001$ \\
\hline Headache & $22.0 \%$ & $21.9 \%$ & 0.897 \\
\hline Neuropathic pain & $19.6 \%$ & $22.7 \%$ & $<0.001$ \\
\hline Depression & $21.0 \%$ & $18.6 \%$ & 0.002 \\
\hline Anxiety & $18.3 \%$ & $19.8 \%$ & 0.049 \\
\hline Arthritis (RA \& OA) & $12.6 \%$ & $21.4 \%$ & $<0.001$ \\
\hline Skin cancers & $13.8 \%$ & $14.9 \%$ & 0.107 \\
\hline Thyroid disease & $12.2 \%$ & $15.1 \%$ & $<0.001$ \\
\hline Diabetes & $8.8 \%$ & $14.8 \%$ & $<0.001$ \\
\hline Sleep disorders & $11.5 \%$ & $11.0 \%$ & 0.469 \\
\hline \multicolumn{4}{|l|}{ Index DMD** } \\
\hline Glatiramer acetate & $33.7 \%$ & & \\
\hline Interferon beta-1a IM & $32.1 \%$ & & \\
\hline Interferon beta-1a SQ & $20.5 \%$ & & \\
\hline Interferon beta-1b & $12.7 \%$ & & \\
\hline Mitoxantrone & $0.6 \%$ & & \\
\hline Natalizumab & $0.4 \%$ & & \\
\hline \multicolumn{4}{|l|}{ Other medications used for treating MS exacerbations } \\
\hline Corticosteroids & $61.4 \%$ & $40.0 \%$ & $<0.001$ \\
\hline Methotrexate & $1.4 \%$ & $2.0 \%$ & 0.020 \\
\hline Azathioprine & $1.3 \%$ & $1.0 \%$ & 0.165 \\
\hline Cyclosporine & $1.2 \%$ & $1.4 \%$ & 0.336 \\
\hline Mycophenolate & $1.1 \%$ & $0.7 \%$ & 0.027 \\
\hline IVIG & $1.3 \%$ & $0.6 \%$ & $<0.001$ \\
\hline Cyclophosphamide & $0.6 \%$ & $0.5 \%$ & 0.416 \\
\hline Muscle relaxants & $37.6 \%$ & $33.6 \%$ & $<0.001$ \\
\hline Antidepressants & $37.9 \%$ & $30.4 \%$ & $<0.001$ \\
\hline Anti-fatigue agents & $32.7 \%$ & $12.5 \%$ & $<0.001$ \\
\hline
\end{tabular}

*ICD-9-CM codes used for these conditions are available on request.

**First DMD on or after the patient's index date.

natalizumab was approved by the US FDA in November 2004, withdrawn in February 2005, and then reapproved for relapsing MS in June 2006.

Other drugs used for acute MS exacerbations but without established evidence of altering the course of disease progression are also shown in Table 2. Glucocorticoids usage was highest in patients receiving DMDs post-index (61.4\%) compared with patients who were not treated with DMDs post-index (40.0\%). Usage of the other agents was generally in $2 \%$ or fewer of patients. No patients were found in this timeframe who had received cladribine, daclizumab, or anti-lymphocyte globulin post-index.

Muscle relaxants, antidepressants, and anti-fatigue agents were frequently prescribed post-index in this population, also shown in Table 2, particularly among DMD-treated patients whose percentage of patients with drug use was significantly higher for all three of these drug classes compared to untreated patients $(\mathrm{p}<0.001)$. Pre-index use of these medications was significantly more prevalent in patients who did not receive DMD treatment (muscle relaxants $16.1 \%$ DMD vs. $20.8 \%$ non- 
DMD, $\mathrm{p}<0.001$; antidepressants $20.3 \%$ DMD vs. 22.2 non-DMD, $\mathrm{p}=0.018$; anti-fatigue agents $3.5 \%$ DMD vs. $5.8 \%$ non-DMD, $\mathrm{p}<0.001$ ).

The mean time to therapy initiation was $5.3 \pm 9.1$ months following the index diagnosis (Table 3). Once started on their index medication, more than threequarters $(78.7 \%)$ of these patients stayed on their index medication without switching to another DMD for the duration of the follow-up period. Nearly three-quarters of patients $(71.0 \%)$ stayed on their index therapy an average of $17.0 \pm 15.9$ months without gaps exceeding 30 days. Including the $21.3 \%$ of patients who switched to another DMD after an average of $14.8 \pm 12.9$ months on their index DMD, patients appeared to remain on all DMD therapy without gaps exceeding 30 days for an average of $18.8 \pm 16.8$ months. (Table 3 )

There were $29.0 \%$ of patients with gaps in therapy exceeding 30 days, and over 16\% with gaps in excess of 60 days (restarting therapy), as shown in Table 3. Overall, $27.7 \%$ of patients discontinued DMD therapy altogether after an average of $17.6 \pm 14.6$ months without restarting any DMD therapy.

Factors with statistically significant associations with the initiation of DMD therapy are shown in Table 4. The hazard ratio denotes the odds that one group of patients was treated with a DMD compared with a reference group of patients, controlling for the influence of other variables in the model and the length of followup. Those variables associated with an increased likelihood of initiating DMD therapy include patient age (the lower the patient age, the higher the odds of being treated), evidence of loss of coordination, and the occurrence of an NMRI or spinal tap prior to the index diagnosis. Factors associated with a decreased likelihood of DMD initiation include higher degrees of comorbidity (per the Deyo-Charlson Comorbidity Index showing a 13 percent decrease for each point rise in the index), headache, sleep disorders, or the occurrence of pressure ulcers prior to the index diagnosis, as well as the preindex use of azathioprine, anti-fatigue medications, or muscle relaxants.

Factors with statistically significant associations with the persistence on DMD therapy are shown in Table 5. Those associated with an increased likelihood of persisting on DMD therapy include female gender, age of 18 to 34, having an HMO insurance plan type, higher degrees of comorbidity (Deyo-Charlson Comorbidity Index), pre-index comorbidities of depression, headache, or urinary tract infection, and pre-index use of antidepressants or muscle relaxants. Factors associated with a decreased likelihood of DMD persistence include age greater than 34 and pre-index neuropathic pain.

\section{Discussion}

This study investigated the demographics, clinical characteristics, and treatment patterns for DMD therapy in an adult managed care population of newly diagnosed MS patients. Patients were followed for an average of

Table 3 Pharmacotherapy Treatment Persistence Patterns

\begin{tabular}{lc}
\hline Persistence Measure & $\begin{array}{c}\text { DMD-treated patients } \\
\text { (n = 4,462) }\end{array}$ \\
\hline Persistence on DMD therapy & Mean \pm SD \\
\hline Days from index diagnosis to 1 ${ }^{\text {st }}$ DMD & $158 \pm 274$ \\
\hline Days of continuous therapy for index DMDs (no gaps > 30 days) & $511 \pm 476$ \\
\hline Days of continuous therapy for all DMDs (no gaps > 30 days) & $565 \pm 503$ \\
\hline Days, first to last for index DMD (with gaps) & $683 \pm 525$ \\
\hline Days, first to last for all DMDs (with gaps) & $798 \pm 540$ \\
\hline Gap analysis for the index DMD & $\%$ of patients \\
\hline No gaps in index therapy > 30 days & $71.0 \%$ \\
\hline Gaps in index therapy of 31-60 days & $20.6 \%$ \\
\hline Gaps in index therapy > 60 days (restarts) & $16.5 \%$ \\
\hline Gaps of 61-90 days & $8.4 \%$ \\
\hline Gaps of 91-120 days & $4.4 \%$ \\
\hline Gaps > 120 days & $8.3 \%$ \\
\hline Mean days to restart (Mean \pm SD) & $159 \pm 151$ \\
\hline Switched from index DMD & $21.3 \%$ \\
\hline Mean days to switch (Mean \pm SD) & $445 \pm 386$ \\
\hline Discontinued all DMDs before end of follow-upt & $27.7 \%$ \\
\hline Mean days to discontinuation (Mean \pm SD) & $527 \pm 437$ \\
\hline
\end{tabular}


Table 4 Factors Associated with Initiation of DMD Therapy

\begin{tabular}{|c|c|c|c|}
\hline Parameter & $\begin{array}{c}\text { Hazard } \\
\text { Ratio }\end{array}$ & $\begin{array}{l}\text { Pr }> \\
\text { ChiSq }\end{array}$ & $\begin{array}{l}\text { Standard } \\
\text { Error }\end{array}$ \\
\hline \multicolumn{4}{|l|}{ Gender (reference: male) } \\
\hline Female & 0.998 & 0.949 & 0.037 \\
\hline \multicolumn{4}{|l|}{ Age group (reference: 18-34) } \\
\hline Age $35-44$ & 0.845 & $<0.001$ & 0.045 \\
\hline Age 45-54 & 0.641 & $<0.001$ & 0.045 \\
\hline Age 55-64 & 0.424 & $<0.001$ & 0.055 \\
\hline Age $65+$ & 0.107 & $<0.001$ & 0.112 \\
\hline \multicolumn{4}{|l|}{ Pre-index comorbidities } \\
\hline $\begin{array}{l}\text { Deyo-Charlson Comorbidity } \\
\text { Index }\end{array}$ & 0.867 & $<0.001$ & 0.020 \\
\hline Loss of coordination & 1.537 & $<0.001$ & 0.080 \\
\hline Headache & 0.797 & $<0.001$ & 0.042 \\
\hline Sleep disorders & 0.781 & 0.002 & 0.079 \\
\hline Pressure ulcer & 0.225 & 0.003 & 0.501 \\
\hline \multicolumn{4}{|l|}{ Pre-index pharmacotherapy } \\
\hline Anti-fatigue agent use & 0.824 & 0.018 & 0.082 \\
\hline Azathioprine use & 0.289 & 0.003 & 0.410 \\
\hline Corticosteroid use & 1.081 & 0.031 & 0.036 \\
\hline Muscle relaxant use & 0.823 & $<0.001$ & 0.042 \\
\hline \multicolumn{4}{|l|}{ Pre-index testing } \\
\hline Electrocardiogram & 0.883 & 0.001 & 0.038 \\
\hline Nuclear MRI & 2.361 & $<0.001$ & 0.035 \\
\hline Spinal tap & 1.819 & $<0.001$ & 0.043 \\
\hline
\end{tabular}

$35.7 \pm 17.5$ months after their index diagnosis. The results indicate that $40.3 \%$ of incident patients received treatment with at least one of the DMDs during the post-index period. Population demographics were similar to a prior study done in a managed care population [32]. Treated patients were primarily in the younger age categories of 18-44 years of age, with DMD therapy initiated an average of $5.3 \pm 9.1$ months after the index diagnosis. Patients most likely to receive DMD therapy were under the age of 45 , had evidence of loss of coordination, and had received NMRI or spinal tap preindex. Once treatment was initiated, $72.3 \%$ of DMDtreated patients remained on therapy for the remainder of their study period.

In the age categories of 18-34 and 35-44, most patients received DMD treatment (64.7\% and 57.0\% respectively), while most patients in the upper age categories did not receive DMD treatment (43\% in ages 45 $54 ; 27.8 \%$ in ages $55-64$; and, $6.6 \%$ in ages $65+$ ). The reasons for the increasing percentages of untreated patients in the older groups are unknown, but disease severity and disease stage are suspected contributors to the decision not to opt for treatment. The use of retrospective claims data in the absence of the patient's medical chart relies on the provider's coding of an MS diagnosis, and contributes a very limited view of the patient's medical history. It is possible that the window of 12 months without MS claims prior to the first observed MS claim may have resulted in misclassification, particularly for patients with long-standing or advanced disease, those in remission, or other patients no longer seeking treatment. The low percentage of DMD treated patients found in this analysis may be due in part to these limitations and methodological issues. More rigorous confirmation of the accuracy of the diagnosis data were unable to be performed due to patient de-identification requirements of the data sources. Differences in the frequency of comorbidities may also be attributable to the differences in age between the DMD-treated and untreated groups, as higher percentages of patients with arthropathies, hypertension, hypercholesterolemia, cancers, UTIs, thyroid disease and diabetes may be expected in the older (untreated) population. In addition, a diagnosis was required in only one claim for indication of a comorbidity in this study, and so the percentage of patients with comorbidities may be overestimated as some diagnosis coding may have been either rule-outs or miscoding.

Adherence with DMDs can be complicated by many factors $[26,33]$, not the least of which are the concomitant medications that patients may need to take for relief of MS symptoms, such as muscle relaxants or anti-fatigue medications, as well as for comorbidities that occur as a normal part of aging. The comorbidities found post-index in this population are often medicated chronically, such as the arthropathies, hypertension, hyperlipidemia, depression, and neuropathic pain. Multiple chronic medications can impose both a motivational as well as financial burden on the patient.

This study found 71.0\% of DMD-treated patients continued their index DMD treatment for $17.0 \pm 15.9$ months without gaps exceeding 30 days, compared to an adherence rate of $62 \%$ to $64 \%$ among patients taking insulin for type 2 diabetes and $68 \%$ to $79 \%$ among patients taking oral medications for heart failure [33]. In this study's cohort of newly diagnosed patients treated with DMDs, there were $27.7 \%$ who discontinued DMD therapy after an average of $17.6 \pm 14.6$ months. Although not directly comparable, Rio et al (2005) found in their cohort of 632 patients followed over 8 years (mean of 47.1 months) that $17 \%$ (107) stopped therapy with approximately half of those stopping prior to 2 years [26], and O'Rourke (2005) found a stopping rate for interferon-beta of $28 \%$, as well as an Italian study of RRMS that noted $41 \%$ of patients treated with interferon-beta had stopped after three years [28]. 
Table 5 Factors Associated with Persistence on DMD Therapy

\begin{tabular}{|c|c|c|c|}
\hline Parameter & Hazard Ratio & $\operatorname{Pr}>$ ChiSq & Standard Error \\
\hline \multicolumn{4}{|l|}{ Gender (reference: Male) } \\
\hline Female & 1.117 & 0.035 & 0.052 \\
\hline \multicolumn{4}{|l|}{ Age group (reference: Age 18-34) } \\
\hline Age $35-44$ & 0.701 & $<0.001$ & 0.060 \\
\hline Age $45-54$ & 0.618 & $<0.001$ & 0.061 \\
\hline Age 55-64 & 0.672 & $<0.001$ & 0.073 \\
\hline Age $65+$ & 0.847 & 0.274 & 0.152 \\
\hline \multicolumn{4}{|c|}{ Insurance plan type (reference: Comprehensive) } \\
\hline $\mathrm{HMO}$ & 1.305 & 0.001 & 0.079 \\
\hline PPO & 0.972 & 0.739 & 0.084 \\
\hline POS & 1.096 & 0.170 & 0.067 \\
\hline POS with Capitation & 1.002 & 0.984 & 0.109 \\
\hline \multicolumn{4}{|l|}{ Pre-index comorbidities } \\
\hline Deyo-Charlson Comorbidity Index & 1.049 & 0.045 & 0.024 \\
\hline Depression & 1.273 & 0.001 & 0.074 \\
\hline Headache & 1.162 & 0.008 & 0.056 \\
\hline Neuropathic pain & 0.844 & 0.003 & 0.058 \\
\hline Urinary tract infection & 1.206 & 0.010 & 0.072 \\
\hline \multicolumn{4}{|l|}{ Pre-index pharmacotherapy } \\
\hline Antidepressant use & 1.137 & 0.018 & 0.055 \\
\hline Muscle relaxant use & 1.175 & 0.005 & 0.057 \\
\hline
\end{tabular}

* This table was created using a Cox Model adjusting for time to DMD Therapy Gap of 31+ Days. The dependent variable was days to DMD therapy gap of 31+ days. Shown in this table are those factors of statistical significance. There were more parameters modeled in each category and others eliminated using backward selection.

Further, this study had $29.0 \%$ of patients with gaps in therapy exceeding 30 days, and over $16 \%$ with gaps in excess of 60 days. The reasons for discontinuance and nonadherence gaps are not known. Costello et al (2008) explored reasons for non-adherence to MS therapy and found the key barriers to adherence to be problems with injecting, perceived lack of efficacy, adverse events, and treatment fatigue [33]. It has also been reported that patients discontinuing treatment may also represent higher disability or worsening response to the treatment [26-28,33].

There is a growing body of evidence that progression of clinical disease occurs following cessation of DMD therapy $[24,25,34]$. Drugs that can increase the convenience or tolerability to DMD treatment for MS patients have the potential to increase the rate of early treatment and overall adherence, offering benefit for those who cannot tolerate or adhere to injectable medications [35-44]. The advent of therapies with increased convenience, tolerability and efficacy is indeed encouraging for advancing the treatment of MS.

\section{Limitations}

This study was subject to a number of limitations. Using administrative claims data in the absence of the patient medical charts, and limiting the look-back period to 12 months of pre-index claims history precluded establishing each patient's long term prior disease history. These factors also obscured a definitive MS diagnosis, the type of MS (e.g., relapsing-remitting, primary progressive), identification of the initial date of an MS diagnosis, therapy occurring prior to the start of the study, disease severity, and the occurrence of relapse. Claims analysis is limited in its ability to account for all possible differences in patients and providers residing in different states. In addition, misclassification errors are possible when relying on diagnosis coding from administrative claims data and where the extent of undercoding of diagnoses is unknown. In the absence of diagnosis coding on pharmacy claims, it was assumed that the drugs shown to be used for treating MS were actually used as such. Further, the data sources did not include information on patient assistance programs or investigational drug treatment programs administered outside of a health plan's coverage or benefit plan, and so only treatments submitted to a health plan for coverage were available for analysis. The databases represent primarily employed or retired individuals, and thus may not be generalizable to the entirety of the US MS population. 


\section{Conclusions}

The decision to initiate DMD treatment, the choice of therapy, and the extended deliberations to continue treatment are complex. Individualized decisions made by each patient with their provider consider many factors including disease severity, benefits of therapy, comparative effectiveness of available therapies, potential side-effects, and the effects on a patient's budget and lifestyle. This study found that a large percentage of newly-diagnosed MS patients remained untreated during the study period, that at least a quarter of treated patients stopped therapy during the time of this study, and one-sixth of treated patients experienced treatment gaps despite the risk of disease progression or a return to pre-treatment disease activity. New pharmacologic agents with increased convenience, tolerability and efficacy have promise for improving the overall quality of life for MS patients and their families.

\section{List of Abbreviations}

(DMD): disease-modifying drug; (EP): evoked potentials; (EPO): exclusive provider organization; (HMO): health maintenance organization; (MRI): magnetic resonance imaging; (MS): multiple sclerosis; (NMRI): nuclear magnetic resonance imaging; (POS): point of service; (PPMS): primary progressive multiple sclerosis; (PPO): preferred provider organization; (PRMS): progressive relapsing multiple sclerosis; (RRMS): relapsing/remitting multiple sclerosis; (SPMS): secondary progressive multiple sclerosis;

\section{Acknowledgements and Funding}

The authors wish to acknowledge the contributions of Nikita Mody Patel, PharmD, Homa Dastani, PhD, and Douglas Woo, MD for their important contributions to this research and manuscript. Dr. Dastani is an employee of Novartis Pharmaceuticals Corporation (Novartis); Dr. Patel was an employee of Novartis Pharmaceuticals Corporation at the time of this research; and Dr. Woo was a paid consultant to Novartis in connection with this research. This study was sponsored by Novartis Pharmaceuticals Corporation, East Hanover, NJ, USA.

\section{Author details}

${ }^{1}$ Thomson Reuters, 332 Bryn Mawr Ave., Bala Cynwyd, PA, 19004, USA. ${ }^{2}$ Thomson Reuters, 4301 Connecticut Ave NW, Suite 330, Washington, DC, 20008, USA. ${ }^{3}$ Health Analytics, LLC, 9200 Rumsey Road, Suite 215, Columbia, MD, 21045, USA. ${ }^{4}$ Novartis Pharmaceuticals, One Health Plaza, USEH 501/ 3990, East Hanover, NJ, 07936, USA.

\section{Authors' contributions}

JM participated in the study concept and design, acquisition and analysis of data, interpretation of data, drafting and revision of the manuscript. RF participated in the study design, acquisition and analysis of data, statistical interpretation of the data, and review and revision of the manuscript. $\mathrm{BHJ}$ participated in the study design, acquisition and analysis of data, interpretation of data, and review and revision of the manuscript. CK reviewed existing literature, researched and wrote the background section of the manuscript, as well as reviewing and editing of the manuscript. KK conceived of the study and participated in its design, analysis of results, and review and revision of the manuscript. All authors read and approved the final manuscript.

\section{Competing interests}

Jay Margolis, Robert Fowler, Barbara Johnson, and Cheryl Kassed (at the time of the study) are employees of Thomson Reuters (Healthcare \& Science), who was paid by Novartis Pharmaceuticals in connection with the development of this manuscript. Kristijan Kahler is an employee of Novartis Pharmaceuticals.
Received: 24 December 2010 Accepted: 6 October 2011

Published: 6 October 2011

\section{References}

1. National Institute of Neurological Disorders and Stroke (NINDS): Multiple Sclerosis: Hope Through Research. [http://www.ninds.nih.gov/disorders/ multiple_sclerosis/detail_multiple_sclerosis.htm].

2. World Health Organization: Atlas of Multiple Sclerosis Resources in the World Geneva: WHO Press; 2008.

3. Orton SM, Herrera BM, Yee IM, Valdar W, Ramagopalan SV, Sadovnick AD, Ebers GC: Sex ratio of multiple sclerosis in Canada: a longitudinal study. Lancet Neurol 2006, 5:932-936.

4. Lublin FD, Reingold SC: National Multiple Sclerosis Society (USA) Advisory Committee on Clinical Trials of New Agents in Multiple Sclerosis. Neurology 1996, 46:907-911, Defining the clinical course of multiple sclerosis: results of an international survey:.

5. Herndon RM, Rudick RA, Cottrell DA: To Treat or Not to Treat in Clinically Isolated Syndrome. Int/ Jrnl MS Care 2009, 11:99-106.

6. National Multiple Sclerosis Society: Diagnosing MS. [http://www. nationalmssociety.org/about-multiple-sclerosis/what-we-know-about-ms/ diagnosing-ms/index.aspx].

7. National Collaborating Centre for Chronic Conditions: Multiple sclerosis. National clinical guideline for diagnosis and management in primary and secondary care. London (UK): National Institute for Clinical Excellence (NICE); 2004, 197, [468 references].

8. Polman $\mathrm{CH}$, Reingold SC, Edan G, Filippi M, Hartung HP, Kappos L, Lublin FD, Metz LM, McFarland HF, O'Connor PW, Sandberg-Wollheim M, Thompson AJ, Weinshenker BG, Wolinsky JS: Diagnostic criteria for multiple sclerosis: 2005 revisions to the "McDonald Criteria". Ann Neurol 2005, 58:840-846.

9. McDonald WI, Compston A, Edan G, Goodkin D, Hartung HP, Lublin FD, McFarland HF, Paty DW, Polman CH, Reingold SC, Sandberg-Wollheim M, Sibley W, Thompson A, van den Noort S, Weinshenker BY, Wolinsky JS: Recommended diagnostic criteria for multiple sclerosis: guidelines from the International Panel on the diagnosis of multiple sclerosis. Ann Neurol 2001, 50:121-127.

10. Trojano M, Paolicelli D: The differential diagnosis of multiple sclerosis: classification and clinical features of relapsing and progressive neurological syndromes. Neurol Sci 2001, 22(Suppl 2):S98-102.

11. Marrie R, Horwitz R, Cutter G, Tyry T, Campagnolo D, Vollmer T: Comorbidity, socioeconomic status and multiple sclerosis. Mult Scler 2008, 14:1091-1098.

12. Marrie RA, Horwitz R, Cutter G, Tyry T, Campagnolo D, Vollmer T: Comorbidity delays diagnosis and increases disability at diagnosis in MS. Neurology 2009, 72:117-124.

13. Pascual AM, Martinez-Bisbal MC, Bosca I, Valero C, Coret F, MartinezGranados B, Marti-Bonmati L, Mir A, Celda B, Casanova B: Axonal loss is progressive and partly dissociated from lesion load in early multiple sclerosis. Neurology 2007, 69:63-67.

14. Miller DH, Grossman RI, Reingold SC, McFarland HF: The role of magnetic resonance techniques in understanding and managing multiple sclerosis. Brain 1998, 121(Pt 1):3-24.

15. Morrissey SP, Miller DH, Kendall BE, Kingsley DP, Kelly MA, Francis DA, MacManus DG, McDonald Wl: The significance of brain magnetic resonance imaging abnormalities at presentation with clinically isolated syndromes suggestive of multiple sclerosis. A 5-year follow-up study. Brain 1993, 116:135-146.

16. Fraser C, Hadjimichael O, Vollmer T: Predictors of adherence to glatiramer acetate therapy in individuals with self-reported progressive forms of multiple sclerosis. J Neurosci Nurs 2003, 35:163-170.

17. O'Riordan Jl, Thompson AJ, Kingsley DP, MacManus DG, Kendall BE, Rudge $\mathrm{P}, \mathrm{McD}$ onald WI, Miller DH: The prognostic value of brain MRI in clinically isolated syndromes of the CNS. A 10-year follow-up. Brain 1998, 121:495-503.

18. Goodin D, Frohman E, Garmany G Jr, Halper J, Likosky W, Lublin F, Silberberg D, Stuart W, van den Noort S: Disease modifying therapies in multiple sclerosis: report of the Therapeutics and Technology Assessment Subcommittee of the American Academy of Neurology and the MS Council for Clinical Practice Guidelines. Neurology 2002, 58:169-178. 
19. Brusaferri F, Candelise L: Steroids for multiple sclerosis and optic neuritis: a meta-analysis of randomized controlled clinical trials. J Neurol 2000, 247:435-442.

20. Menge T, Weber MS, Hemmer B, Kieseier BC, von Budingen $H C$, Warnke $C$, Zamvil SS, Boster A, Khan O, Hartung HP, Stuve O: Disease-modifying agents for multiple sclerosis: recent advances and future prospects. Drugs 2008, 68:2445-2468.

21. National Multiple Sclerosis Society: Disease Management Consensus Statement. National Clinical Advisory Board 2007, 1-8.

22. Wiendl H, Toyka KV, Rieckmann P, Gold R, Hartung HP, Hohlfeld R: Basic and escalating immunomodulatory treatments in multiple sclerosis: current therapeutic recommendations. J Neurol 2008, 255:1449-1463.

23. National Institute for Health and Clinical Excellence (NICE): Management of multiple sclerosis in primary and secondary care - CG8 Multiple sclerosis: full guidance.[http://guidance.nice.org.uk/CG8/Guidance/pdf/ English].

24. Richert ND, Zierak MC, Bash CN, Lewis BK, McFarland HF, Frank JA: MRI and clinical activity in MS patients after terminating treatment with interferon beta-1b. Mult Scler 2000, 6:86-90.

25. Cox D, Stone J: Managing self-injection difficulties in patients with relapsing-remitting multiple sclerosis. J Neurosci Nurs 2006, 38:167-171.

26. Rio J, Porcel J, Tellez N, Sanchez-Betancourt A, Tintore M, Arevalo MJ, Nos C, Montalban X: Factors related with treatment adherence to interferon beta and glatiramer acetate therapy in multiple sclerosis. Mult Scler 2005, 11:306-309.

27. Tremlett HL, Oger J: Interrupted therapy: stopping and switching of the beta-interferons prescribed for MS. Neurology 2003, 61:551-554.

28. O'Rourke KE, Hutchinson M: Stopping beta-interferon therapy in multiple sclerosis: an analysis of stopping patterns. Mult Scler 2005, 11:46-50.

29. Ruggieri RM, Settipani N, Viviano L, Attanasio M, Giglia L, Almasio P, La Bella V, Piccoli F: Long-term interferon-beta treatment for multiple sclerosis. Neurol Sci 2003, 24:361-364.

30. Biogen Idec, Elan Pharmaceuticals: Tysabri (natalizumab) prescribing information. November 2009. [.[http://www.tysabri.com/tysbProject/tysb. portal/_baseur/threeColLayout/SCSRepository/en_US/tysb/home/index.xml].

31. EMD Serono, Inc. Novantrone (mitoxantrone hydrochloride) prescribing information. 2009.

32. Ozminkowski RJ, Marder WD, Hawkins K, Wang S, Stallings SC Finkelstein SN, Sinskey AJ, Wierz D: The Use of Disease-Modifying New Drugs for Multiple Sclerosis Treatment in Private-Sector Health Plans. Clin Ther 2004, 26:1341-1354.

33. Costello K, Kennedy P, Scanzillo J: Recognizing Nonadherence in Patients With Multiple Sclerosis and Maintaining Treatment Adherence in the Long Term. Medscape J Med 2008, 10:225.

34. Durelli $L$, Clerico M: The importance of maintaining effective therapy in multiple sclerosis. J Neurol 2005, 252(Suppl 3):iii38-iii43.

35. drugdevelopment-technology.com: Fingolimod - Novel Therapy for Multiple Sclerosis. [http://www.drugdevelopment-technology.com/projects/ fingolimod/].

36. Food and Drug Administration: Study: Novartis' Fingolimod Superior to Avonex. [http://www.fdanews.com/newsletter/article? articleld $=113110$ \&issueld $=122421$.

37. National Institutes of Health: Minocycline in Clinically Isolated Syndromes (CIS). [http://www.clinicaltrials.gov/ct2/show/NCT00666887?term $=$ phase+3+multiple+sclerosis+oral\&rank $=5]$.

38. Giuliani F, Hader W, Yong W: Minocycline attenuates T cell and microglia activity to impair cytokine production in T cell-microglia interaction. $J$ Leukoc Biol 2005, 78:135-143.

39. National Institutes of Health: List of clinical trials with teriflunomide. [http://clinicaltrials.gov/ct2/results?term = teriflunomide].

40. Warnke C, Meyer Zu Horste G, Hartung HP, Stuve O, Kieseier BC: Review of teriflunomide and its potential in the treatment of multiple sclerosis. Neuropsychiatr Dis Treat 2009, 5:333-340

41. Promising outcomes from Phase III CLARITY study for the treatment of multiple sclerosis announced. Expert Rev Pharmacoecon Outcomes Res 2009, 9:198, No authors listed.

42. National Institutes of Health: Oral Cladribine in Early Multiple Sclerosis (MS) (ORACLE MS). [http://www.clinicaltrials.gov/ct2/show/NCT00725985? term $=$ cladribine+multiple+sclerosis\&rank $=1]$.

43. Preiningerova J: Oral laquinimod therapy in relapsing multiple sclerosis. Expert Opin Investig Drugs 2009, 18:985-989.
44. National Institutes of Health: Safety and Efficacy of Orally Administered Laquinimod for Treatment of Relapsing Remitting Multiple Sclerosis (RRMS) (ALLEGRO). [http://clinicaltrials.gov/ct2/show/NCT00509145?term = laquinimod\&rank $=4]$.

\section{Pre-publication history}

The pre-publication history for this paper can be accessed here: http://www.biomedcentral.com/1471-2377/11/122/prepub

doi:10.1186/1471-2377-11-122

Cite this article as: Margolis et al:: Disease-modifying drug initiation patterns in commercially insured multiple sclerosis patients: a retrospective cohort study. BMC Neurology 2011 11:122.

\section{Submit your next manuscript to BioMed Central and take full advantage of:}

- Convenient online submission

- Thorough peer review

- No space constraints or color figure charges

- Immediate publication on acceptance

- Inclusion in PubMed, CAS, Scopus and Google Scholar

- Research which is freely available for redistribution

Submit your manuscript at www.biomedcentral.com/submit
Biomed Central 